\title{
The effect of aerosolized indomethacin on lung inflammation and injury in a rat model of blunt chest trauma
}

\author{
Capt (Navy) Raymond L. Kao, \\ $\mathrm{MD}, \mathrm{MPH}$ \\ Weixiong Huang, MD \\ Claudio M. Martin, MD, MSc \\ Tao Rui, MD, PhD
}

This study was presented at the Canadian Military Veteran and Health Research Forum, Nov. 21, 2016, Vancouver, BC

Accepted Oct. 2, 2018

Correspondence to:

R.L. Kao

Victoria Hospital

London ON N6A 5W9

raymond.kao@Ihsc.on.ca

DOI: $10.1503 /$ cjs. 014318

\begin{abstract}
Background: Acute lung contusion from blunt chest trauma (BCT) is characterized by an intense inflammatory response in the pulmonary parenchyma, which is associated with acute lung injury (ALI), acute respiratory distress syndrome and ventilatorassociated pneumonia. We hypothesized that aerosolized indomethacin may reduce pulmonary inflammation and ALI in a rat model of BCT.
\end{abstract}

Methods: Sprague-Dawley rats were anesthetized and received a tracheotomy for administration of aerosolized medication through a catheter. The BCT procedure involved free-dropping a hollow metal weight $(200 \mathrm{~g})$ from a height of 25.5 , 38.3 or $51.2 \mathrm{~cm}$ onto the right thorax. We administered $1 \mathrm{mg} / \mathrm{kg}$ of indomethacin or $1 \mathrm{~mL} / \mathrm{kg}$ of saline intratracheally 15 minutes after BCT. The sham group had a similar procedure without the exposure to BCT and treatment. Three hours postimpact, we obtained arterial blood gas and analyzed bronchoalveolar lavage for protein concentration, polymorphonuclear leukocytes (PMN) and cytokine levels, and lung tissue samples were taken for histopathological analysis.

Results: The rats' mean arterial pressure and heart rate dropped immediately postimpact but recovered close to that of the sham group after 30 minutes in both control and treatment groups. Compared to BCT alone, indomethacin significantly reduced the total protein level in the lungs $(1.06 \pm 0.39 \mathrm{mg} / \mathrm{mL} \mathrm{v.} 3.75 \pm 1.95 \mathrm{mg} / \mathrm{mL}$, $p=0.006)$ and alveolar FD-70 leak $(0.23 \pm 0.19 \mu \mathrm{g} / \mathrm{mL}$ v. $0.53 \pm 0.19 \mu \mathrm{g} / \mathrm{mL}, p=$ $0.02)$. Indomethacin also significantly attenuated the acute inflammatory response in percent PMN $(13.33 \pm 7.5 \%$ v. $28.0 \pm 12.96 \%, p=0.04)$. Tumour necrosis factor $-\alpha$ and interleukin-6 decreased in the indomethacin group, but the decreases were not significant compared with other groups.

Conclusion: Aerosolized indomethacin has a protective effect against alveloar tissue permeability and inflammatory response induced by BCT.

Contexte : La contusion pulmonaire aiguë causée par un traumatisme thoracique fermé (TTF) se caractérise par une intense réaction inflammatoire dans le parenchyme pulmonaire, liée à une atteinte pulmonaire aiguë (APA), à un syndrome de détresse respiratoire et à la pneumonie associée à la ventilation mécanique. Nous avons émis l'hypothèse que l'indométacine en aérosol pouvait réduire l'inflammation pulmonaire et l'APA dans un modèle murin de TTF.

Méthodes : Des rats Sprague-Dawley ont été anesthésiés et ont subi une trachéotomie pour l'administration du médicament en aérosol par un cathéter. Le TTF a été infligé par un poids de métal creux (200 g) en chute libre d'une hauteur de 25,5, 38,3 ou $51,2 \mathrm{~cm}$ sur le thorax droit. Nous avons administré $1 \mathrm{mg} / \mathrm{kg}$ d'indométacine ou $1 \mathrm{~mL} / \mathrm{kg}$ de solution saline dans la trachée 15 minutes après le TTF. Un groupe a été soumis à une intervention similaire fictive, sans exposition au TTF ni au traitement. Trois heures après l'impact, nous avons obtenu des gaz artériels et analysé le liquide de lavage bronchoalvéolaire pour connaitre les taux de protéines, de leucocytes polymorphonucléaires (PMN) et de cytokines; nous avons aussi prélevé des échantillons de tissu pulmonaire pour des analyses histopathologiques.

Résultats : La pression artérielle et la fréquence cardiaque moyennes des rats ont immédiatement chuté après l'impact, mais sont revenues près des valeurs du groupe soumis à l'intervention fictive après 30 minutes dans le groupe témoin et le groupe traité. Comparativement au TTF seul, l'indométacine a significativement réduit le taux de protéines totales dans les poumons $(1,06 \pm 0,39 \mathrm{mg} / \mathrm{mL}$ c. $3,75 \pm$ $1,95 \mathrm{mg} / \mathrm{mL}, p=0,006)$ et la fuite alvéolaire de FD-70 $(0,23 \pm 0,19 \mu \mathrm{g} / \mathrm{mL}$ c. $0,53 \pm$ $0,19 \mu \mathrm{g} / \mathrm{mL}, p=0,02)$. L'indométacine a aussi significativement atténué la réaction 
inflammatoire aiguë en pourcentage de $\mathrm{PMN}(13,33 \pm 7,5 \%$ c. $28,0 \pm 12,96 \%, p=$ $0,04)$. Le facteur de nécrose tumorale $\alpha$ et l'interleukine- 6 ont diminué dans le groupe sous indométacine, mais ces baisses n'ont pas été significatives comparativement aux autres groupes.

Conclusion : L'indométacine en aérosol exerce un effet protecteur contre la perméabilité du tissu alvéolaire et la réaction inflammatoire induite par le un TTF.

lunt chest trauma (BCT) is one of the most common injuries in trauma patients; it accounts for $20 \%-25 \%$ of adult deaths, ${ }^{1}$ and pulmonary contusion (PC) is a common finding in those cases. ${ }^{2}$ Pulmonary contusion, which is an independent risk factor for the development of pneumonia, acute lung injury (ALI), acute respiratory distress syndrome (ARDS), ventilatorassociated pneumonia and long-term respiratory disability, is usually caused by BCT, but can also result from explosion injuries or a shock wave., ${ }^{2,3}$ Immediately after exposure to BCT, the disruption of alveoli induces intra-alveolar hemorrhage along with interstitial hemorrhage. Blood extravasation initiates a cascade of reactions that involve activation and release of various vasoactive and proinflammatory factors. This innate inflammatory response triggered by BCT involves the recruitment of blood leukocytes and the activation of tissue macrophages, which subsequently release a series of inflammatory mediators, including cytokines, proteolytic enzymes and components of coagulation cascades. These inflammatory mediators synergistically lead to increased alveolar capillary membrane permeability and microvascular leakage that induce pulmonary edema, ventilation/perfusion mismatching, increased intrapulmonary shunting and a loss of lung compliance., ${ }^{4,5}$

The clinical consequences of PC vary widely, ranging from mild dyspnea to prolonged mechanical ventilation and ARDS. ${ }^{6,7}$ There is still no effective pharmacological approach to treating BCT related to PC; the choices of treatments in such patients are generally limited and include basic supportive tools such as supplemental oxygen and cardiopulmonary monitoring. ${ }^{8,9}$ The development of PC is characterized by intense inflammation in the alveolar space and noncardiogenic pulmonary edema caused by the outpouring of proteinacious fluid from the pulmonary microcirculation. This inflammatory response also has a delayed clinical consequence: it primes inflammatory cells for exaggerated response to any subsequent insults, such as second hit phenomena. ${ }^{10}$ Therefore, treatments aiming at the anti-inflammatory progress ${ }^{11-13}$ and improving epithelial function ${ }^{14,15}$ might become the key elements to accelerate recovery and decrease mortality among patients with ALI or ARDS due to PC.

The present experimental animal study aimed to examine the effects of aerosolized indomethacin on the severity of BCT from in vivo observation of the leukocyte recruitment and alveolar capillary permeability in rat pulmonary microcirculation. We hypothesized that inhaled indomethacin may have a beneficial effect on PC caused by BCT.

\section{Methods}

\section{Animal preparation}

The studies were performed on Sprague-Dawley rats weighing 250-300 g. The animals were anesthetized with intraperitoneal injections of sodium pentobarbital (55 $\mathrm{mg} / \mathrm{kg}$; Sigma), and the temperature of the rats was monitored and maintained at $36^{\circ} \mathrm{C}-37.5^{\circ} \mathrm{C}$ using a heating pad and lamp throughout the experiment. The right carotid artery and jugular vein were cannulated with PE-50 polyethylene tubing (Becton Dickinson Company). The mean arterial pressure (MAP) and heart rate (HR) were measured via the arterial line using a pressure transducer (78353A; Hewlett Packard), and the jugular vein was used for the administration of Rhodamine-6G and/or FD-70 (Sigma). Following BCT, the rats received a tracheotomy, and a 14-G plastic catheter was inserted for administration of inhaled indomethacin.

\section{Impact energy assessment for optimal pulmonary injuries}

Rats were fixed on an acrylic glass platform in the supine position, with all 4 legs attached to the platform with sticky tape. To prevent direct myocardial injury, the blunt impact was distributed only on the right side of the thorax. A hollow metal weight $(200 \mathrm{~g})$ was free-dropped from a height of $25.5,38.3$, or $51.2 \mathrm{~cm}$ onto the right chest without any protective shield. The impact energy generated via this mechanism was calculated with the equation $E=m g h$, where $E$ is energy, $m$ is mass of the cylindrical weight $(0.20 \mathrm{~kg}), g$ is gravity $\left(9.8 \mathrm{~m} / \mathrm{s}^{2}\right)$ and $b$ is the height of the free drop $(25.5,38.3$, or $51.2 \mathrm{~cm})$. Total energy transferred to the right side of the rats' chest wall was 0.5 , 0.75 , and $1.0 \mathrm{~J}$, respectively.

\section{Experimental design}

After obtaining the optimal energy impact to the chest wall, the animals were randomized to the following experimental groups: sham $(n=8)$, BCT $(n=8)$, BCT + aerosolized normal saline $(n=8)$ and BCT + aerosolized indomethacin $(n=8)$. Either normal saline $(1 \mathrm{~mL} / \mathrm{kg})$ or indomethacin $(1 \mathrm{mg} / \mathrm{kg}$, Fresenius Kabi Canada) was administered intratracheally 15 minutes after exposure to BCT using the MicroSprayer Aerosolizer (Model IA1B-R, Penn-Century, Inc.). Arterial blood gas (ABG) for 
$\mathrm{pH}$ and partial pressures of oxygen $\left(\mathrm{PaO}_{2}\right)$ and carbon dioxide $\left(\mathrm{PaCO}_{2}\right)$ were obtained at 2 time points for each of the groups: 15 minutes and 180 minutes after BCT. In each study phase, animals were euthanized 3 hours post$\mathrm{BCT}$, the chest was opened to assess the macro degree of lung injury, and bronchoalveolar lavage fluid (BALF) was collected to analyze pulmonary protein concentration, polymorphonuclear leukocytes (PMNs) and cytokine concentration, and tissue samples were taken for histopathological analysis.

\section{Bronchoalveolar lavage fluid collection}

We collected BALF from euthanized rats at indicated time points by instilling and withdrawing $10 \mathrm{~mL}$ of icecold sterile phosphate buffered saline (PBS) 3 times from the whole lungs via an intratracheal cannula. In the indomethacin group, only $5 \mathrm{~mL}$ of PBS was used to lavage the injured right side of lung. The BALF samples were centrifuged at $500 \mathrm{~g}$ for 10 minutes at $4^{\circ} \mathrm{C}$, and the supernatants were frozen at $-80^{\circ} \mathrm{C}$ for subsequent measurements of protein concentration, cytokine levels and total white blood cell counts as well as its cell differential, which was enumerated on cytospin-prepared slides stained with Giemsa (Sigma). Tumour necrosis factor (TNF)- $\alpha$ and interleukin (IL)-6 levels in BALF were determined using ELISA kits (BD OptEIA, BD Biosciences) according to the manufacturer's instructions.

\section{Pulmonary epithelial permeability}

The lung permeability was evaluated using both protein concentration and FD-70 level. Protein concentration in BALF was determined with the micro bicinchoninic acid (BCA) method (Pierce) according to the manufacturer's instructions. In separate experimental rat groups, a $1 \mathrm{mg} / \mathrm{kg}$ intravenous bolus of a fluorescein isothiocyanate-labelled dextran (FD-70; Sigma) was injected 30 minutes before samples of BALF were obtained. The FD-70 concentrations were measured in the BALF with a fluorescence spectrophotometer (Perkin-Elmer LS50), using excitation and emission wavelengths of 482 and $521 \mathrm{~nm}$, respectively.

Posthypotonic lysis of the red blood cells and the total white blood cell count of each BALF sample was determined using a grid hemocytometer. The differential cell counts were enumerated after cytosine centrifugation $(1000 \mathrm{~g}$ for $10 \mathrm{~min})$ with prepared slides and then stained with Giemsa (Sigma). A total of 200 cells for each experimental condition were examined, and the percentage of $\mathrm{PMN}$ was calculated.

The ELISA cytokine assays on the BALF for TNF- $\alpha$ and IL-6 (OptEIA Human ELISA Sets, Pharmingen) were performed according to the instructions recommended by the manufacturer.

\section{Histological evaluation of the pulmonary tissue}

The lung tissue samples were fixed in $10 \%$ formalin immediately after removal from the chest cavity. The lung tissues were then dehydrated in graded concentrations of ethanol followed by the clearing agent xylene to remove the water and ethanol before they were embedded in paraffin. Tissue sections $5 \mathrm{~mm}$ in thickness were obtained and then stained with hematoxylin-eosin. Slides (magnification $\times 100$, Carl Zeiss Axiovert 200M microscope) were evaluated and graded for the presence of interstitial neutrophilic infiltrate, intra-alveolar hemorrhage and pulmonary edema. Histopathological evaluation was scored by a blinded and experienced laboratory pathologist using a 5-point scale according to combined assessment of alveolar congestion, hemorrhage, infiltration or aggregation of neutrophils in the airspace or vessel walls, and thickness of alveolar wall/hyaline membrane formation (0 indicates minimum damage; $1+$, mild damage; $2+$, moderate damage; $3+$, severe damage and $4+$, maximum damage $\left.{ }^{16}\right)$.

\section{Statistical analysis}

All data are presented as means \pm standard deviations (SD). Statistical analysis was performed with one-way analysis of variance followed by Bonferroni correction for multiple comparisons; we used the Student $t$ test for 2-group comparisons. All analyses were performed using SAS software version 9.3 (SAS Institute Inc.). All tests presented are 2 -sided, and we considered results to be significant at $p<$ 0.05 . We used the $F$ test to assess the equality of variance. If $p \geq 0.05$, then we did not reject the null hypothesis that the 2 variances were equal, and we used the $p$ value from the pooled analysis. However, we rejected the null hypothesis that the 2 variances were equal if $p<0.05$. We used the Satterthwaite method for unequal variance.

\section{Results}

\section{Optimal energy impact}

Table 1 shows the degree of injury using a method similar to that of Chavko and colleagues. ${ }^{17}$ Lung lesions were classified from 0 to 3 , with 0 indicating healthy lungs;

\begin{tabular}{|c|c|c|c|c|}
\hline $\begin{array}{l}\text { Impact } \\
\text { energy }\end{array}$ & $\begin{array}{l}\text { Right lung } \\
\text { injuries, no. }\end{array}$ & $\begin{array}{l}\text { Left lung } \\
\text { injuries, no. }\end{array}$ & $\begin{array}{c}\text { Right lung } \\
\text { injuries grading } \\
\pm \text { SEM }\end{array}$ & $\begin{array}{c}\text { Deaths } \\
\text { no. }\end{array}$ \\
\hline Sham & 0 & 0 & $1.00 \pm 0.00$ & 0 \\
\hline $0.5 \mathrm{~J}$ & 5 & 0 & $2.13 \pm 0.35$ & 0 \\
\hline $0.75 \mathrm{~J}$ & 8 & 0 & $3.50 \pm 0.42$ & 0 \\
\hline $1.0 \mathrm{~J}$ & 10 & 1 & $3.88 \pm 0.40$ & 2 \\
\hline
\end{tabular}


1 indicating trace and scattered hemorrhagic spot; 2 indicating moderate, extensive parenchymal contusion; and 3 indicating confluent hepatized regions. There was an energy-dependent association between increasing impact of energy and the extension of lung injury. We found increased BALF protein concentrations with the enhanced impact energy to blunt chest, indicating a correlation between worsening lung injury and increasing energy impact (sham v. $0.5 \mathrm{~J}: 0.26 \pm 0.13 \mathrm{mg} / \mathrm{mL}$ vs. $0.62 \pm$ $0.50 \mathrm{mg} / \mathrm{mL}, p>0.99$; sham v. $0.75 \mathrm{~J}: 0.26 \pm 0.13 \mathrm{mg} / \mathrm{mL}$ v. $1.31 \pm 0.95 \mathrm{mg} / \mathrm{mL}, p=0.01$; sham v. $1.0 \mathrm{~J}: 0.26 \pm$ $0.13 \mathrm{mg} / \mathrm{mL}$ v. $1.87 \pm 1.02 \mathrm{mg} / \mathrm{mL}, p=0.03$; Fig. 1$)$. We found similar results when examining the recruitment of the PMNs to alveoli space (sham v. $0.5 \mathrm{~J}: 1.00 \% \pm 1.07 \%$ v. $4.13 \% \pm 7.32 \%, p>0.99$; sham v. $0.75 \mathrm{~J}: 1.00 \% \pm$ $1.07 \%$ v. $14.0 \% \pm 9.97 \%, p=0.01$; sham v. $1.0 \mathrm{~J}: 1.00 \% \pm$ $1.07 \%$ v. $12.57 \% \pm 8.66 \%, p=0.04$; Fig. 2 ). At the $1.0 \mathrm{~J}$

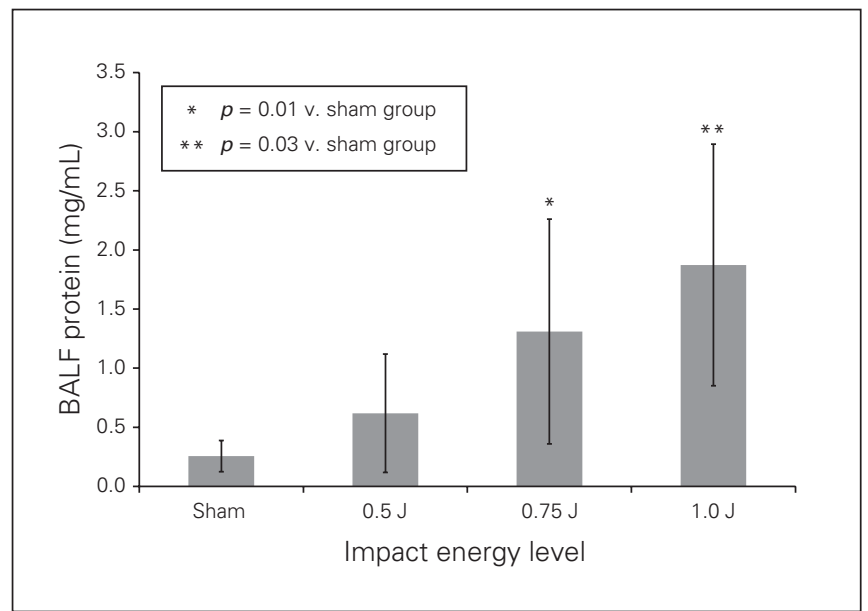

Fig. 1. Total protein levels in bronchoalveolar lavage fluid (BALF) at 3 hours post-blunt chest trauma after isolated pulmonary contusion injury with chest impact energy levels of $0.5 \mathrm{~J}, 0.75 \mathrm{~J}$, and $1.0 \mathrm{~J}$. Values are means \pm standard deviations for $n=8$ rats.

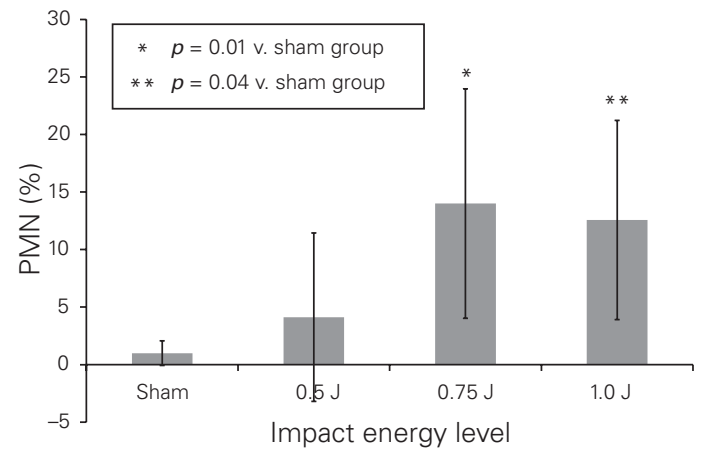

Fig. 2. The percentage of polymorphonuclear leukocyte (PMN) in bronchoalveolar lavage fluid (PMN numbers $\div$ total numbers of leukocytes at 3 hours post-blunt chest trauma after isolated pulmonary contusion with chest impact energies of $0.5 \mathrm{~J}, 0.75 \mathrm{~J}$, and $1.0 \mathrm{~J}$. Values are means \pm standard deviations for $n=8$ rats. impact energy, 2 rats died and 1 rat sustained injury to the left lung. Thus, the impact energy of $0.75 \mathrm{~J}$ from a distance of $38.3 \mathrm{~cm}$ height was the optimum impact energy for our BCT model.

\section{Effect of inhaled indomethacin on rat hemodynamics}

We monitored the alteration of mean arterial pressure (MAP) and heart rate (HR) throughout the experiments in the rat BCT models. As shown in Figure 3, in all 3 BCT groups MAP and HR decreased significantly immediately after the impact. But both MAP and HR recovered close to the baseline measures in the sham group approximately 60 minutes postimpact.

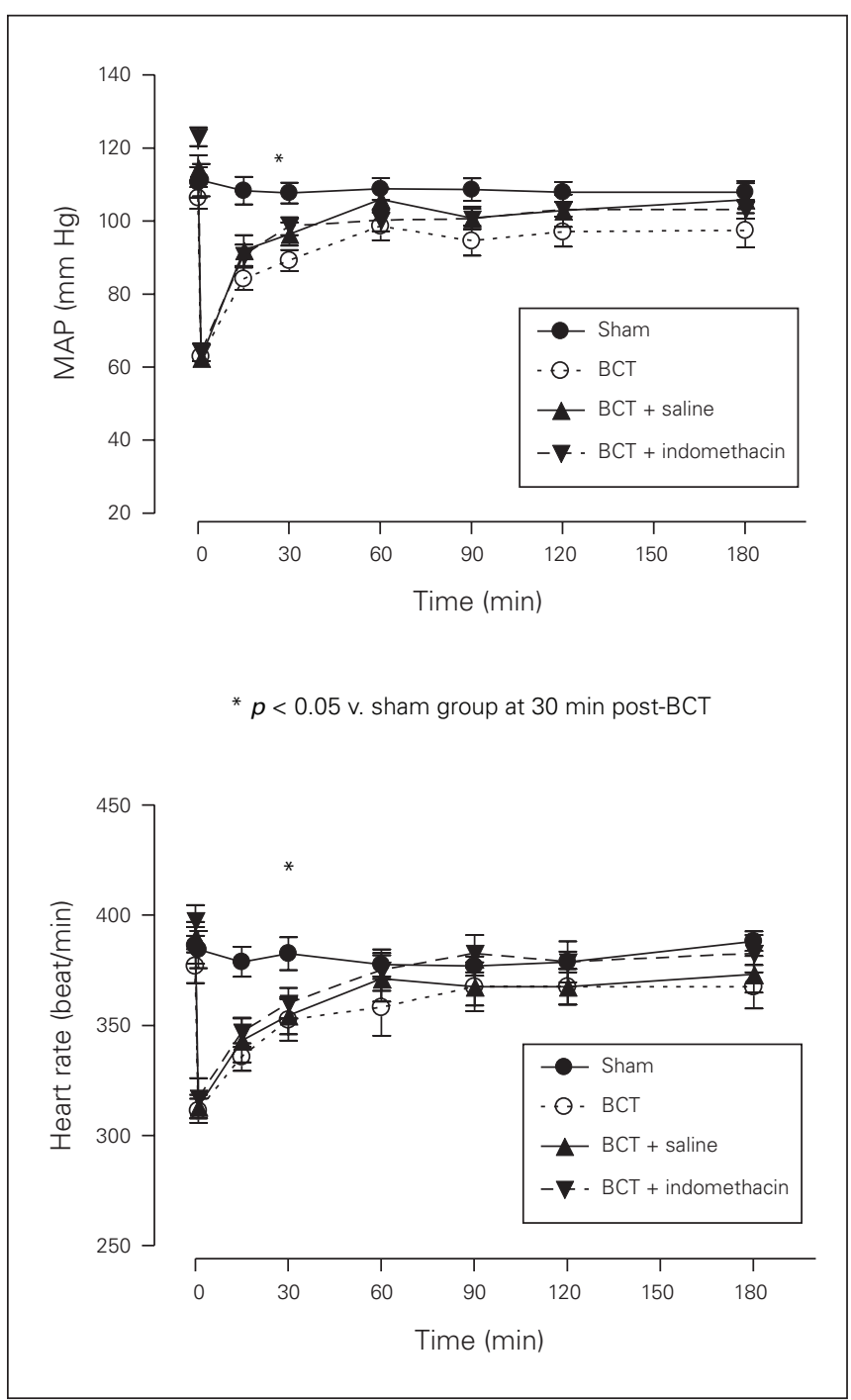

Fig. 3. Mean arterial pressure (MAP) and heart rate (HR) reading at 3 hours post-blunt chest trauma (BCT) for the 4 rat groups. Sham, BCT, BCT + saline, and BCT + indomethacin groups were subjected to a blunt energy impact of $0.75 \mathrm{~J}$. All physiological variables were recorded for 180 minutes following BCT. Values are means \pm standard deviations for $n=8$ rats. 
The ABG at 15 minutes post-BCT showed a significant drop in $\mathrm{pH}$ between the sham group and the BCT + indomethacin group $(7.46 \pm 0.03$ v. $7.41 \pm 0.02, p=0.03)$, but no significant drop between the sham group and the BCT group $(7.46 \pm 0.03$ v. $7.44 \pm 0.05, p>0.99)$ or between the sham group and the BCT + saline group $(7.46 \pm 0.03 \mathrm{v}$. $7.41 \pm 0.03, p=0.05)$. At 180 minutes post-BCT, there were no differences among the groups (Fig. 4A). No differences among the groups were observed for $\mathrm{PaCO}_{2}$ at 15 and 180 minutes post-BCT (Fig. 4B), but at 15 minutes post-BCT there was a significant decrease in $\mathrm{PaO}_{2}$ between the sham group and the BCT group (483.25 \pm $50.05 \mathrm{~mm} \mathrm{Hg}$ v. $247.13 \pm 94.12 \mathrm{~mm} \mathrm{Hg}, p<0.001)$, between the sham group and the BCT + saline group
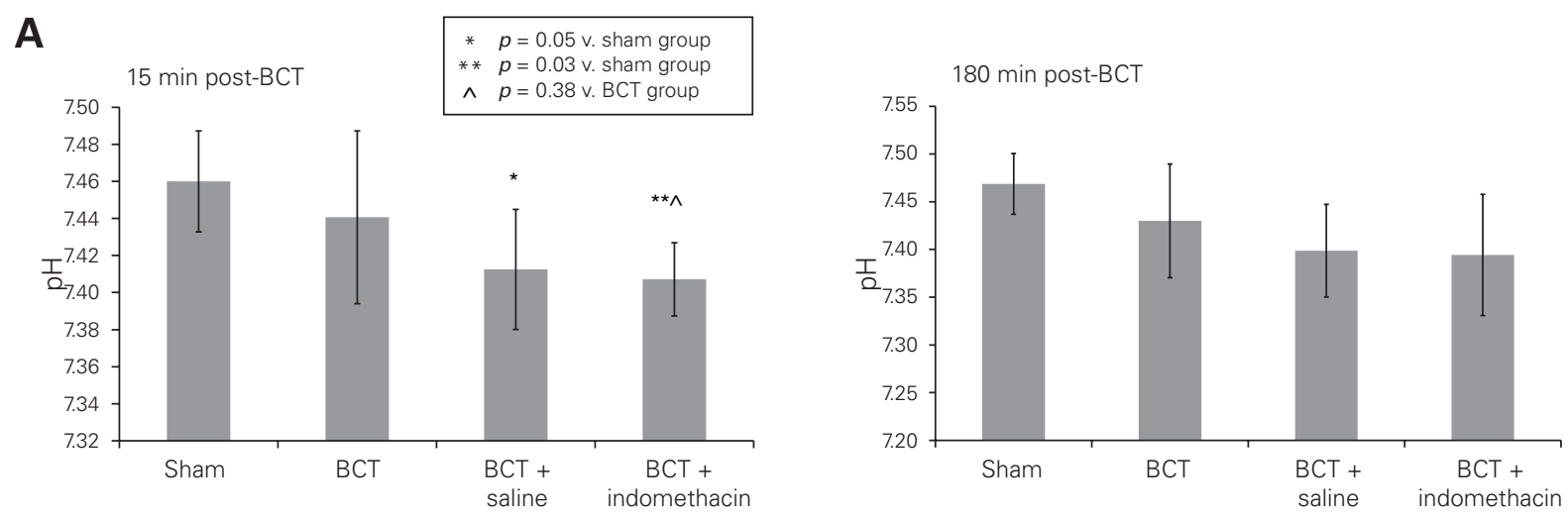

B
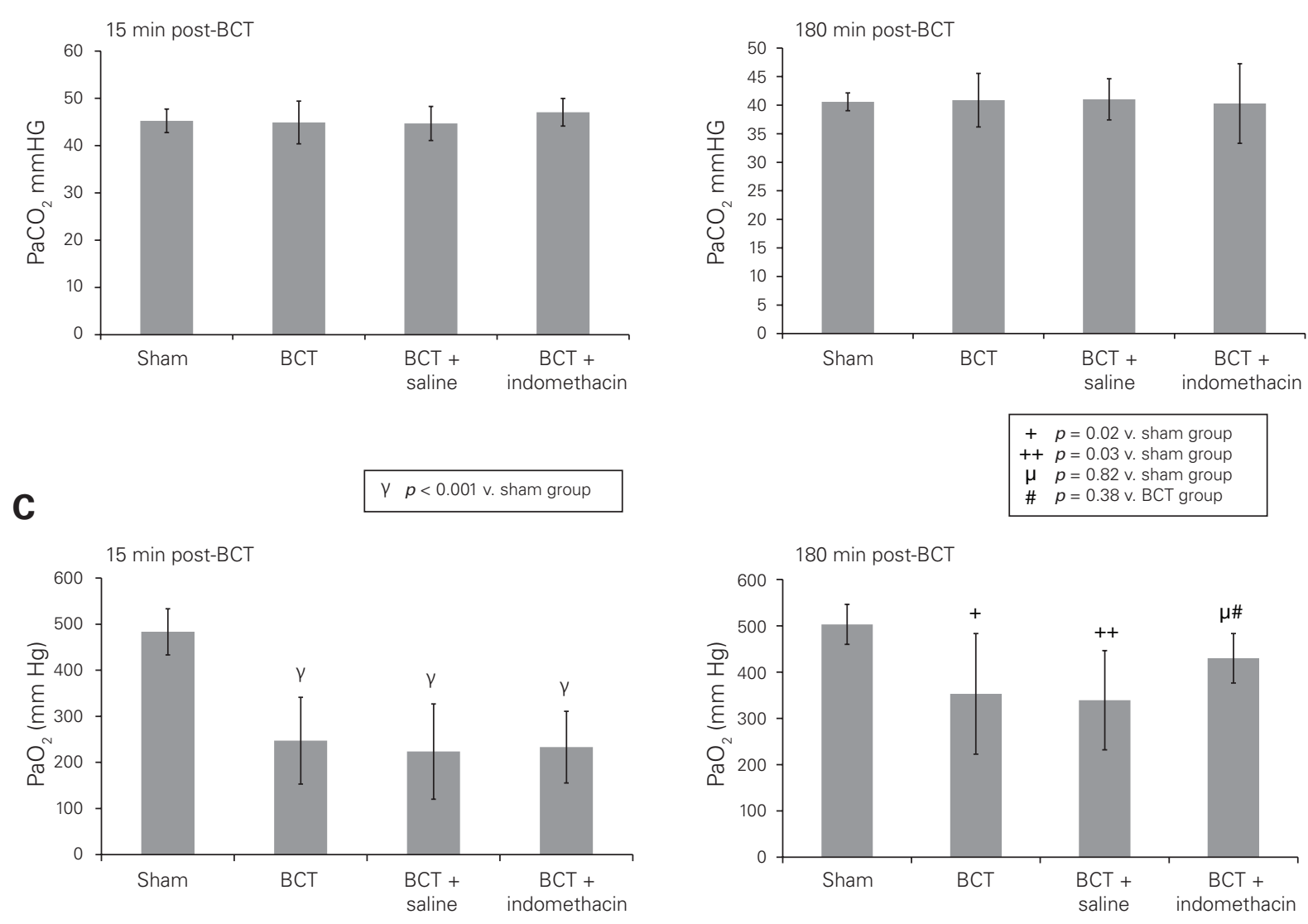

Fig. 4. Arterial blood gas measurements: $\mathrm{pH}, \mathrm{PaCO}_{2}$ and $\mathrm{PaO}_{2}$ for the 4 rat groups. Sham, $\mathrm{BCT}$ (blunt chest trauma), $\mathrm{BCT}+\mathrm{saline}$, and $\mathrm{BCT}+$ indomethacin groups were subjected to a blunt energy impact of $0.75 \mathrm{~J}$. (A) pH at 15 and 180 minutes post-BCT. (B) PaCO ${ }_{2}$ at 15 and 180 minutes post-BCT. (C) $\mathrm{PaO}_{2}$ at 15 and 180 minutes post-BCT. Values are means \pm standard deviations for $n=8$ rats. 
$(483.25 \pm 50.05 \mathrm{mmHg}$ v. $223.5 \pm 103.35 \mathrm{mmHg}, p<0.001)$ and between the sham group and the BCT + indomethacin group $(483.25 \pm 50.05 \mathrm{mmHg}$ v. $233.13 \pm 77.76 \mathrm{mmHg}, p<$ 0.001). At 180 minutes post-BCT, the $\mathrm{PaO}_{2}$ for both the $\mathrm{BCT}$ group and the BCT + saline group continued to be significantly decreased compared with that of the sham group $(503 \pm 43.20 \mathrm{mmHg}$ v. $352.88 \pm 130.30 \mathrm{mmHg}, p=$ 0.02 and $503 \pm 43.20 \mathrm{mmHg}$ v. $339.13 \pm 107.18 \mathrm{mmHg}, p=$ 0.009 , respectively), but the $\mathrm{PaO}_{2}$ in the $\mathrm{BCT}+$ indomethacin group was not significantly decreased compared with that of the sham group $(429.71 \pm 53.47 \mathrm{~mm} \mathrm{Hg} \mathrm{v.} 503 \pm$ $43.20 \mathrm{~mm} \mathrm{Hg}, p=0.82$ ) or the BCT group (429.71 \pm $53.47 \mathrm{mmHg}$ v. $352.88 \pm 130.29 \mathrm{mmHg}, p=0.38)$.

\section{Pulmonary interstitial permeability}

Indomethacin decreased the pulmonary permeabilityinduced BCT. As shown in Figure 5, both the BCT group and the BCT + saline group had a significant increase in BALF protein and FD-70 compared with the sham group and the BCT + indomethacin group; however, in the $\mathrm{BCT}+$ indomethacin group, protein and FD-70 did not differ significantly from those of the sham group (BALF protein, sham v. BCT: $0.39 \pm 0.24 \mathrm{mg} / \mathrm{mL}$ v. $3.75 \pm$ $1.95 \mathrm{mg} / \mathrm{mL}, p=0.005$; sham v. BCT + saline: $0.39 \pm$ $0.24 \mathrm{mg} / \mathrm{mL}$ v. $4.01 \pm 1.85 \mathrm{mg} / \mathrm{mL}, p=0.0002$; sham v. BCT + indomethacin: $0.39 \pm 0.24 \mathrm{mg} / \mathrm{mL}$ v. $1.06 \pm$ $1.09 \mathrm{mg} / \mathrm{mL}, p>0.99$; BCT v. BCT + indomethacin: 3.75 $\pm 1.95 \mathrm{mg} / \mathrm{mL}$ v. $1.06 \pm 1.09 \mathrm{mg} / \mathrm{mL}, p=0.006$; Fig. 5 A; and FD-70, sham v. BCT: $0.10 \pm 0.09 \mathrm{mg} / \mathrm{mL}$ v. $0.53 \pm$ $0.19 \mathrm{mg} / \mathrm{mL}$; sham v. BCT + saline: $0.10 \pm 0.09 \mathrm{mg} / \mathrm{mL} \mathrm{v}$. $0.57 \pm 0.23 \mathrm{mg} / \mathrm{mL}, p=0.0001$; sham v. BCT + indometh- acin: $0.10 \pm 0.09 \mathrm{mg} / \mathrm{mL}$ v. $0.23 \pm 0.19 \mathrm{mg} / \mathrm{mL}, p>0.99$; BCT v. BCT + indomethacin: $0.53 \pm 0.19 \mathrm{mg} / \mathrm{mL}$ v. 0.23 $\pm 0.19 \mathrm{mg} / \mathrm{mL}, p=0.02$; Fig. $5 \mathrm{~B}$ ).

\section{Alveolar white blood cells, PMNs and inflammatory markers}

There was no significant increase in the total white blood cell count of BALF post-PC, but it was characterized by a significant increase of PMNs (Fig. 6), which indicated the inflammatory response in the injured lung. The percentage of PMNs decreased significantly in the BCT + indomethacin group compared with the BCT group (13.33\% $\pm 7.5 \%$ v. $28.0 \% \pm 12.96 \%, p=0.04$; Fig. $6 \mathrm{~B})$. The inflammatory mediators TNF- $\alpha$ and IL- 6 increased in all 3 BCT groups, but the decreases in both mediators in the $\mathrm{BCT}+$ indomethacin group were not significant compared with the BCT group and the BCT + saline group (Fig. 7A and B).

\section{Pulmonary histology}

Microscopic evaluation of lung samples revealed severe intra-alveolar, intrabronchial and subpleural hemorrhages as well as interstitial edema and atelectasis in all 3 BCT groups, whereas lung specimens from the sham group were considered intact. However, there was significant improvement in the BCT + indomethacin group. Based on the scoring system by $\mathrm{Wu}$ and colleagues, ${ }^{16}$ the microscopic evaluation of the histopathological slides was as follows: sham group $=0, \mathrm{BCT}$ group $=4, \mathrm{BCT}+$ saline group $=3$, and BCT + indomethacin group $=1-2$ (Fig. 8).

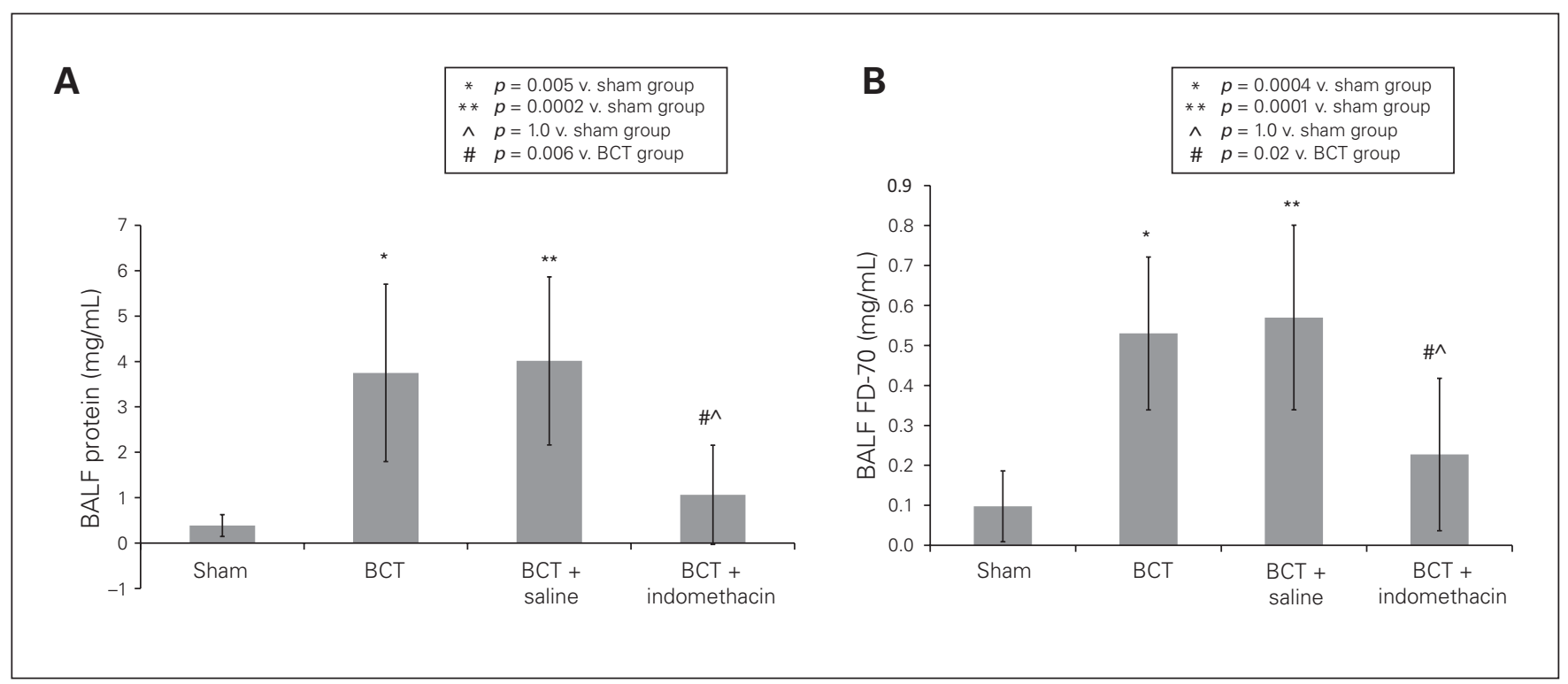

Fig. 5. Interstitial lung permeability: bronchoalveolar lavage fluid (BALF) alveolar protein concentration and FD-70 at 3 hours postblunt chest trauma (BCT) for the 4 rat groups. Sham, BCT, BCT + saline, and BCT + indomethacin groups were subjected to a blunt energy impact of $0.75 \mathrm{~J}$. Both (A) alveolar protein concentration and (B) FD-70 levels in BALF were significantly reduced with administration of indomethacin. Values are means \pm standard deviations for $n=8$ rats. 


\section{Discussion}

Blunt chest wall trauma causes PC and a subsequent complex sequence of events, including direct tissue injury and activation of both local and systemic inflammatory mechanisms leading to significant morbidity and mortality. ${ }^{18-22}$ This study explored the optimal energy impact to the chest wall to elicit optimal macro and micro pulmonary injuries and evaluated the effect of inhaled indomethacin on those injuries. Using the optimal $0.75 \mathrm{~J}$ impact energy, at 15 minutes postimpact the rats were given either inhaled normal saline or liquid form of indomethacin. At 3 hours post-treatment, the $\mathrm{PaO}_{2}$ of the BCT + indomethacin group improved significantly compared with the BCT group and the BCT + saline group, although it did not return to the baseline measure of the sham group.

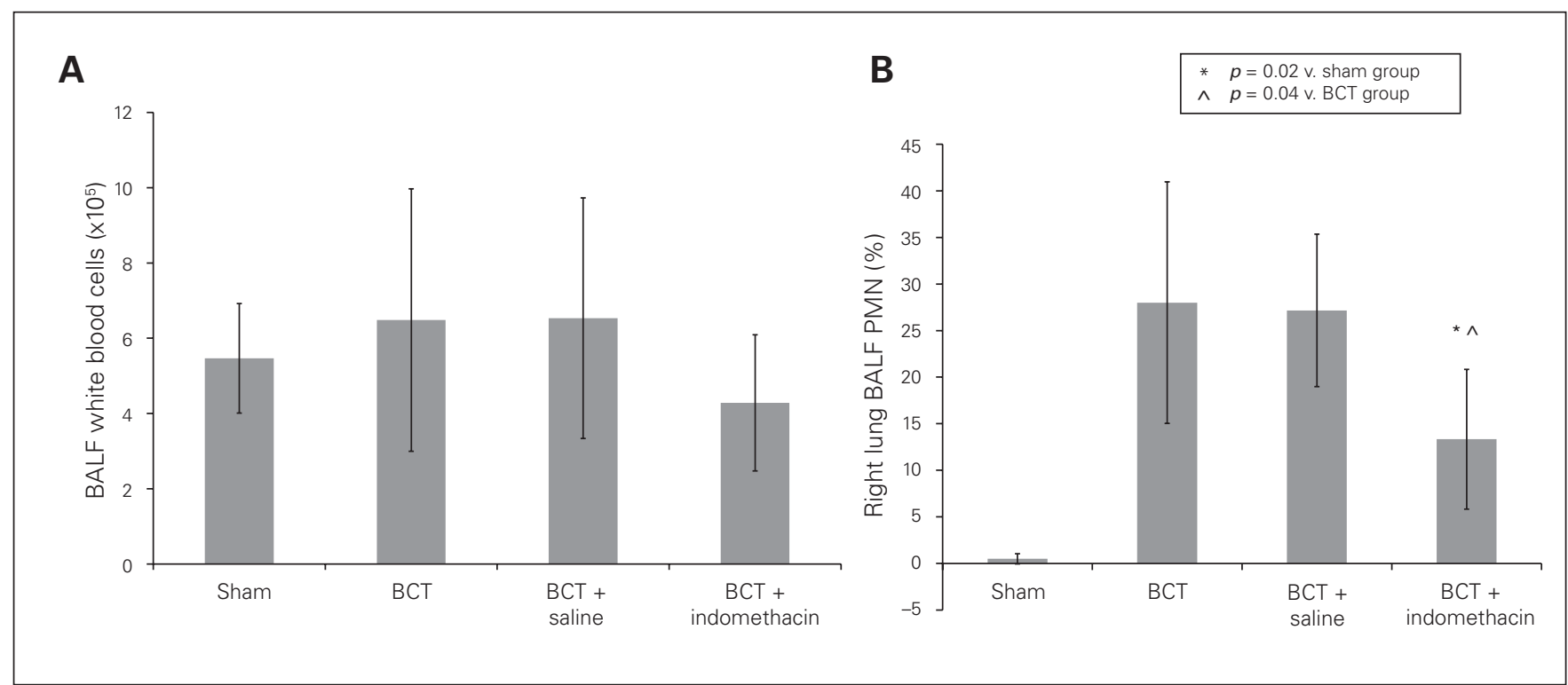

Fig. 6. (A) Bronchoalveolar lavage fluid (BALF) pulmonary white blood cell count and (B) polymorphonuclear leukocytes (PMN) percentage at 3 hours post-blunt chest trauma (BCT) for the 4 rat groups. Sham, BCT, BCT + saline, and BCT + indomethacin groups were subjected to a blunt energy impact of $0.75 \mathrm{~J}$. There were significant increases in the PMN percentage, but not in the total white blood cell count. The BCT-induced increase in PMNs was reduced significantly by indomethacin administration compared with the sham and BCT groups. Values are means \pm standard deviations for $n=8$ rats.

A

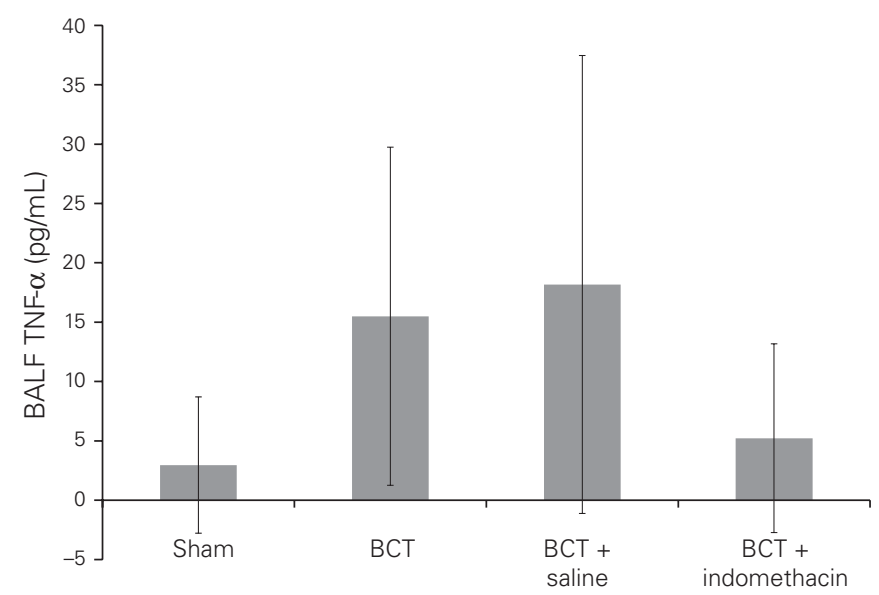

B

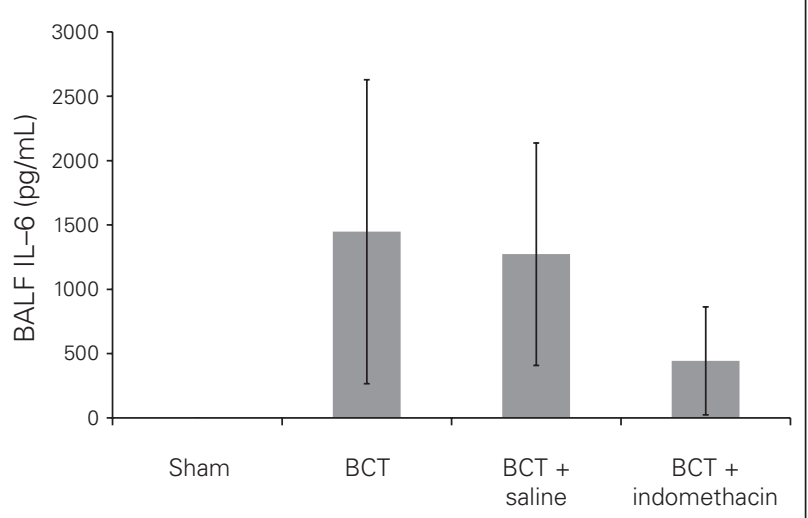

Fig. 7. Bronchoalveolar lavage fluid (BALF) (A) tumour necrosis factor (TNF)- $\alpha$ and (B) interleukin (IL)-6 at 3 hours post-blunt chest trauma (BCT). Sham, BCT, BCT + saline, and BCT + indomethacin groups were subjected to a blunt energy impact of $0.75 \mathrm{~J}$. The TNF- $\alpha$ and IL- 6 concentrations were measured using ELISA. Values are means \pm standard deviations. 

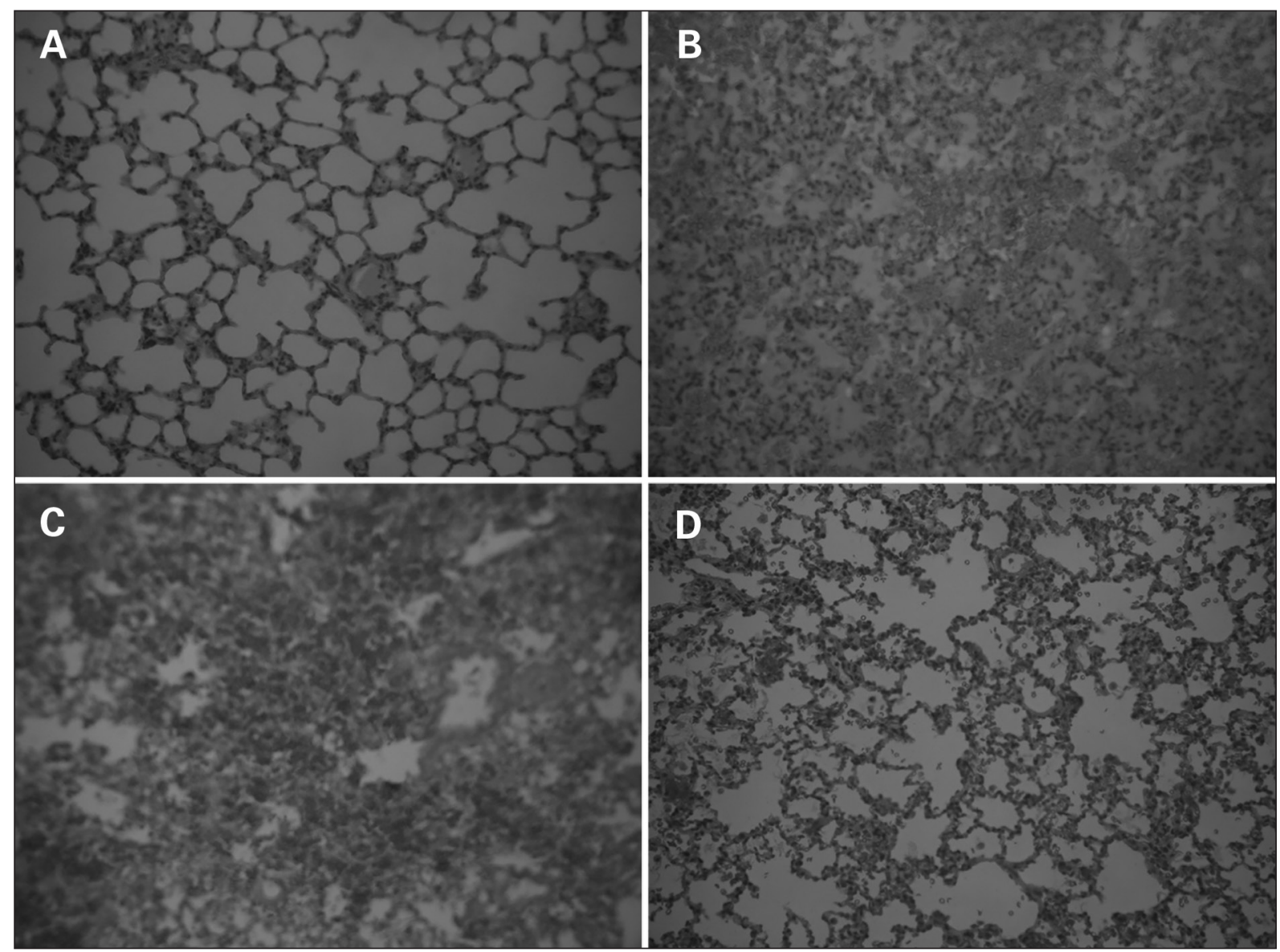

Fig. 8. Pulmonary histopathology using hematoxylin and eosin stain (magnification $\times 100$ ). We found infiltration of inflammatory cells, intra-alveolar hemorrhage, high levels of intra-alveolar exudates and interstitial edema in the blunt groups. The indomethacin-treated group showed a comparatively milder inflammatory cellular infiltrate and intraalveolar hemorrhage. (A) Normal rat lung histology. (B) Histopathology of a rat with blunt chest trauma (BCT). (C) Histopathology of a rat with BCT + saline. (D) Histopathology of a rat with BCT + indomethacin.

The white blood cells in BALF did not differ among the groups, but there was a significant decrease in PMNs in the BCT + indomethacin group compared with the BCT group. Similarly, there was a significant decrease in the pulmonary interstitial leak in the BCT + indomethacin group (alveolar protein and intravenous injected FD-70). There was also significant decrease in pulmonary inflammatory markers (TNF- $\alpha$ and IL-6) in the BCT + indomethacin group. Macroscopically, the histological findings indicated a significant decrease in the pulmonary hemorrhagic findings in the BCT + indomethacin group. These findings suggest that indomethacin treatment decreases the severity of the pulmonary injury.

Nonsteroidal anti-inflammatory drugs (NSAIDs) are a heterogeneous group of drugs with often chemically unrelated but similar therapeutic properties. They are among the most frequently used class of medications; as of 2009 NSAIDs represented a market worth more than $\$ 9$ billion among prescribed medications in the United States. ${ }^{23}$ At varying doses, NSAIDs can alleviate the swelling, redness and pain induced by inflammation processes; they can also reduce general fever and absolve headaches. Early studies by Piper and Vane ${ }^{24,25}$ revealed a dose-dependent inhibition of prostaglandin formation by acetylsalicylic acid (ASA), indomethacin and sodium salicylate, and found indomethacin to be the most potent and sodium salicylate the least potent. Nonsteroidal anti-inflammatory drugs are cyclooxygenase (COX) inhibitors. Cyclooxygenase is the key enzyme in prostaglandin $\mathrm{H} 2$ (PGH-2) production from arachidonic acid. PGH-2 is the metabolite converted into prostanoids (prostaglandin, prostacyclins and thromboxanes). The COX enzymes have 2 isoforms: COX-1 and COX-2. COX-1 is expressed in most tissues and it serves as a housekeeping enzyme to maintain normal cell homeostasis. COX-2 is expressed in a limited number of organs during normal physiologic conditions, but its expression is inducible as a result of inflammation stimuli and cytokines in migratory and other cells. ${ }^{26}$ It has been suggested that the anti-inflammation activities of NSAIDs are due to the inhibition of COX-2, while the unwanted adverse effects are due to the inhibition of COX-1. ${ }^{27}$ Indomethacin at antiinflammatory doses was found to have high gastrointestinal 
toxicity, as it has more potency against COX-1 than COX$2 .{ }^{28}$ In in vivo and in vitro models of prostaglandin synthesis, the relative potencies of NSAIDs are indomethacin $>$ naproxen $>$ ibuprofen $>$ phenylbutazone $>$ ASA. ${ }^{29}$

Lyophilized intravenous indomethacin is indicated to be used for a hemodynamically significant patent ductus arteriosus (PDA) in premature infants weighing between $500 \mathrm{~g}$ and $1750 \mathrm{~g}$ when, after 48 hours, usual medical management is ineffective. Patent ductus arteriosus is a risk factor for the development of pulmonary hemorrhage in preterm infants. ${ }^{30-32}$ Two retrospective, single-centre studies reported high mortality after pulmonary hemorrhage in infants with very low birth weight. ${ }^{33,34}$ Indomethacin prophylaxis seems to reduce early serious hemorrhage, mainly through its action on the PDA, but it may be less effective in preventing serious pulmonary hemorrhage that occurs after the first week of life. ${ }^{35}$ Furthermore the administration of drugs directly into the lungs has been used in many therapeutic areas. The modern devices available in the market are divided into 3 groups: nebulizer, dose-metering inhaler system and dry powder inhalers. All of these inhalers have evidence of shortcomings. ${ }^{36}$ An aerosol is defined as suspension of liquid or solid in a gaseous medium. ${ }^{37}$ Aerosol delivery has advantages: it delivers medications directly to where they are needed, and it avoids first pass effect with minimum reduction of bioavailability. The field of aerosolized drug application included treatment of lung disease like asthma, chronic obstructive pulmonary disease, cystic fibrosis and lung cancer. The aerosol delivery system has also expanded into the realm of system drug delivery. ${ }^{38}$ The optimal target within the lungs for delivery of drugs to the systemic circulation is the alveolar region owing to its large absorptive surface area, thin air-blood barrier and vascular epithelium coupled with low first-pass metabolism; its enzymatic activity could achieve very high bioavailability for aerosolized drug therapy. ${ }^{39}$ Also, the lung deposition route can be a good alternative for the administration of poorly soluble substances ${ }^{36}$; approximately one-third of the modern drugs are waterinsoluble or poorly water-soluble. Many of the currently injectable formulations can cause adverse effects owing to the detergents and other agents used for solubilization. Indomethacin has a low water solubility $(25 \mathrm{mg} / \mathrm{L})$, thus it can be considered for lung delivery via aerosol treatment.

Clemedson ${ }^{40}$ described the 3 basic phenomena that appear to contribute to the incidence of PCs from BCT. The first is the spalling effect resulting from shearing and bursting at the interface between a gas and a liquid or between media with large differences in density. When aircontaining organs such as the lungs are exposed to a blunt force, the spalling effect causes the disruption of the alveolus at the point of initial contact with the shock wave. The second phenomenon is the inertial effect that occurs when low-density alveolar tissue is stripped from heavier hilar tissues because the 2 types of tissues accelerate at different rates in response to the blunt injury. The third phenomenon is the implosion effect that results from rebound or overexpansion of gas bubbles as the pressure wave passes from the blunt trauma. In addition to those 3 effects, the pulmonary parenchyma may also be torn by excessive distension. The parenchyma lung injury leads to pathophysiological changes; the severity depends on the extent of the injury, which may also lead to respiratory failure. Further hemorrhage into the lung segments may cause bronchospasm and may compromise lung function. Associated increases in the production of mucous and decreases in the production of surfactant by injured alveolar tissues also contribute to pulmonary dysfunction. ${ }^{41}$ Furthermore, segmental lung injury from BCT can result in ventilation/perfusion mismatch, worsening intrapulmonary shunt, increases in lung fluids and loss of lung compliance. ${ }^{42}$ These pathological changes can cause clinical hypoxemia, hypercarbia and increased work of breathing. In our experimental rats, the clinical pathological changes that occurred were mainly a ventilation/perfusion mismatch, causing a decrease in the $\mathrm{PaO}_{2}$, but not the $\mathrm{PaCO}_{2}$, which is supported by the fact that the injury was isolated blunt right-sided lung trauma and the impact revealed macro and micro injuries, but was not likely severe enough to cause a significant degradation of the rat lung compliance.

Pulmonary contusion is an independent risk factor for ALI. The innate immune mechanisms activated with an extensive release of inflammatory mediators post-BCT are present not only in the lungs, but also systemically., ${ }^{4,43,44}$ Following PC, the structural damage from disruption of the alveolar capillary membrane causes a rapid increase in BALF protein on the injured lung. ${ }^{11}$ In the present study, we showed that both BALF protein and FD-70 were increased 30 minutes after the injection into the rats' vein post-BCT. With inhaled indomethacin, there was a significant decrease in the BALF protein and FD-70, suggesting a decrease in the structural damage of the alveolar membrane and that prostanoids are released soon after a unilateral PC and initiate an inflammatory response. There was also an increase in local white blood cells, particularly PMNs, which produce various inflammatory mediators leading to the breakdown of the pulmonary capillary basement membrane, hypoxia, increased pulmonary capillary resistance, myocardial dysfunction, toxic metabolites and altered inflammatory cell function. ${ }^{45}$ The activation, localization and extravasation of PMNs from circulation to the site of injury is a complex process that is thought to depend on early response of cytokine expression via production of chemotactic molecules such as chemokines, complement component $5 \mathrm{a}$ and leukotriene $\mathrm{B} 4$ and the upregulation of cell-adhesion molecules such as Intercellular Adhesion Molecule $1 .^{46}$ Subsequently, the accumulation of activated PMNs in the interstitium and alveolar space can result in the production of reactive oxygen species, eicosanoids, cationic proteins and proteolytic enzymes, leading to acute 
inflammation. ${ }^{45,46}$ Lung inflammation and systemic inflammatory responses also depend on toll-like receptor 4 (TLR4) activation during PC. ${ }^{47}$ TLR4 activates intracellular signal transduction, which releases proinflammatory cytokines ${ }^{48}$ such as TNF- $\alpha$, IL-6, chemokines and other proinflammatory mediators involved in the lung injury. ${ }^{44,49,50}$ The localized inflammatory response seen in the lungs bears no resemblance to that of the systemic response measured in the serum, and it is the magnitude of this localized inflammatory response that has been associated with the onset of local organ failure such as ALI/ ARDS and infection. ${ }^{51,52}$ The effect of aerosolized indomethacin on the proinflammatory cytokines, in particular TNF- $\alpha$ and IL- 6 , as the source for pulmonary inflammation post-BCT was effective in decreasing the levels in the BALF. This also suggests that, although indomethacin has no effect on the total white blood cell count, PMN infiltration sustains the initial inflammatory response, which results in the production of eicosanoids, which in turn can be attenuated by aerosolized indomethacin..$^{53}$

\section{Conclusion}

An impact energy of $0.75 \mathrm{~J}$ is the best optimized for pulmonary injuries in this BCT rat model. Inhaled indomethacin treatment appears to improve the $\mathrm{PaO}_{2}$ at 180 minutes post-BCT, decrease pulmonary interstitial permeability to pulmonary protein and FD-70, and decrease pulmonary neutrophils but not TNF- $\alpha$, IL-6 and pulmonary histology post-BCT. Further studies are warranted to determine the potential mechanisms for these observations and to determine whether this improvement can result in decreased pulmonary complications such as ALI/ARDS, thus reducing morbidity and mortality in patients with severe BCT.

Affiliations: From the Department of National Defense, Royal Canadian Medical Services, Ottawa, Ont. (Kao); Critical Care Western, Department of Medicine, Schulich School of Medicine and Dentistry, Western University, London, Ont. (Kao, Martin, Rui); and the Centre for Critical Illness Research, Lawson Health Research Institute, London, Ont. (Kao, Martin, Rui).

\section{Competing interests: None declared.}

Contributors: All authors designed the study. W. Huang acquired and analyzed the data, which R. Kao and T. Rui also analyzed. R. Kao wrote the article, which all authors reviewed and approved for publication.

Data sharing: No additional data are available.

Disclaimer: The views expressed in this paper are those of the authors and do not constitute the views or policies of the Canadian Armed Forces.

\section{References}

1. Hildebrand F, Giannoudis PV, Griensven M, et al. Management of polytraumatized patients with associated blunt chest trauma: a comparison of two European countries. Injury 2005;36:293-302.

2. Cohn SM. Pulmonary contusion: review of the clinical entity. 7 Trauma 1997;42:973-9.

3. Sasser SM, Sattin RW, Hunt RC, et al. Blast lung injury. Prehosp Emerg Care 2006;10:165-72.
4. Raghavendran K, Notter RH, Davidson BA, et al. Lung contusion: inflammatory mechanisms and interaction with other injuries. Shock 2009;32:122-30.

5. Türüt H, Ciralik H, Kilinc M, et al. Effects of early administration of dexamethasone, $\mathrm{N}$-acetylcysteine and aprotinin on inflammatory and oxidant-antioxidant status after lung contusion in rats. Injury 2009; 40:521-7.

6. DePalma RG, Burris DG, Champion HR, et al. Blast injuries. NEngl 7 Med 2005;352:1335-42.

7. Miller PR, Croce MA, Bee TK, et al. ARDS after pulmonary contusion: accurate measurement of contusion volume identifies high-risk patients. F Trauma 2001;51:223-8.

8. Kelly ME, Miller PR, Greenhaw JJ, et al. Novel resuscitation strategy for pulmonary contusion after severe chest trauma. 7 Trauma 2003; 55:94-105.

9. van Wessem KJ, Hennus MP, van Wagenberg L, et al. Mechanical ventilation increases the inflammatory response induced by lung contusion. 7 Surg Res 2013;183:377-84.

10. Hoth JJ, Martin RS, Yoza BK, et al. Pulmonary contusion primes systemic innate immunity responses. 7 Trauma 2009;67:14-21.

11. Davis KA, Fabian TC, Croce MA, et al. Prostanoids: early mediators in the secondary injury that develops after unilateral pulmonary contusion. F Trauma 1999;46:824-31.

12. Chavko M, Adeeb S, Ahlers ST, et al. Attenuation of pulmonary inflammation after exposure to blast overpressure by $\mathrm{N}$-acetylcysteine amide. Shock 2009;32:325-31.

13. Akdemir HU, Guzel A, Kati C, et al. The evaluation of different treatment protocols for trauma-induced lung injury in rats. 7 Thorac Dis 2014;6:66-73.

14. Perkins GD, Nathani N, McAuley DF, et al. In vitro and in vivo effects of salbutamol on neutrophil function in acute lung injury. Thorax 2007;62:36-42.

15. Uhlig C, Silva PL, Ornellas D, et al. The effects of salbutamol on epithelial ion channels depend on the etiology of acute respiratory distress syndrome but not the route of administration. Respir Res 2014;15:56.

16. Wu X, Song X, Li N, et al. Protective effects of dexmedetomidine on blunt chest trauma-induced pulmonary contusion in rats. 7 Trauma Acute Care Surg 2013;74:524-30.

17. Chavko M, Prusaczyk WK, McCarron RM. Lung injury and recovery after exposure to blast overpressure. 7 Trauma 2006;61:933-42.

18. Rodrigues RS, Miller PR, Bozza FA, et al. FDG-PET in patients at risk for acute respiratory distress syndrome: a preliminary report. Intensive Care Med 2008;34:2273-8.

19. Schroeder JE, Weiss YG, Mosheiff R. The current state in the evaluation and treatment of ARdS and SIRS. Injury 2009;40(Suppl 4):S82-9.

20. Kishikawa M, Yoshioka T, Shimazu T, et al. Pulmonary contusion causes long-term respiratory dysfunction with decreased functional residual capacity. 7 Trauma 1991;31:1203-8.

21. Hardaway RM. A brief overview of acute respiratory distress syndrome. World 7 Surg 2006;30:1829-34.

22. Miller PR, Croce MA, Kilgo PD, et al. Acute respiratory distress syndrome in blunt trauma: identification of independent risk factors. Am Surg 2002;68:845-50.

23. Melnikova I. Pain market. Nat Rev Drug Discov 2010;9:589-90.

24. Piper PJ, Vane JR. Release of additional factors in anaphylaxis and its antagonism by anti-inflammatory drugs. Nature 1969;223:29-35.

25. Vane JR. The use of isolated organs for detecting active substances in the circulating blood. Br 7 Pharmacol Chemother 1964;23:360-73.

26. Flower RJ. The development of COX2 inhibitors. Nat Rev Drug Discov 2003;2:179-91.

27. Vane JR, Botting RM. Mechanism of action of nonsteroidal antiinflammatory drugs. Am F Med 1998;104(3A):2S-8S.

28. Vane JR, Botting RM. New insights into the mode of action of anti-inflammatory drugs. Inflamm Res 1995;44:1-10. 
29. Yeh KC. Pharmacokinetic overview of indomethacin and sustainedrelease indomethacin. Am F Med 1985;79(4C):3-12.

30. Garland J, Buck R, Weinberg M. Pulmonary hemorrhage risk in infants with a clinically diagnosed patent ductus arteriosus: a retrospective cohort study. Pediatrics 1994;94:719-23.

31. Finlay ER, Subhedar NV. Pulmonary haemorrhage in preterm infants. Eur F Pediatr 2000;159:870-1.

32. Kluckow M, Evans N. Ductal shunting, high pulmonary blood flow, and pulmonary hemorrhage. 7 Pediatr 2000;137:68-72.

33. Tomaszewska M, Stork E, Minich NM, et al. Pulmonary hemorrhage: clinical course and outcomes among very low-birth-weight infants. Arch Pediatr Adolesc Med 1999;153:715-21.

34. Pandit PB, O’Brien K, Asztalos E, et al. Outcome following pulmonary haemorrhage in very low birthweight neonates treated with surfactant. Arch Dis Child Fetal Neonatal Ed 1999;81:F40-4.

35. Alfaleh K, Smyth JA, Roberts RS, et al. Prevention and 18-month outcomes of serious pulmonary hemorrhage in extremely low birth weight infants: results from the trial of indomethacin prophylaxis in preterms. Pediatrics 2008;121:e233-8.

36. Onischuk AA, Tolstikova TG, Sorokina IV, et al. Anti-inflammatory effect from indomethacin nanoparticles inhaled by male mice. 7 Aerosol Med Pulm Drug Deliv 2008;21:231-43.

37. Colbeck I, Lazaridis M. Aerosols and environmental pollution. Naturwissenschaften 2010;97:117-31.

38. Laube BL. The expanding role of aerosols in systemic drug delivery, gene therapy and vaccination: an update. Transl Respir Med 2014;2:3.

39. Dhanani J, Fraser JF, Chan HK, et al. Fundamentals of aerosol therapy in critical care. Crit Care 2016;20:269.

40. Clemedson CJ. Blast injury. Physiol Rev 1956;36:336-54.

41. Demling RH, Pomfret EA. Blunt chest trauma. New Horiz 1993;1:402-21.

42. Oppenheimer L, Craven KD, Forkert L, et al. Pathophysiology of pulmonary contusion in dogs. 7 Appl Physiol 1979;47:718-28.
43. Hoth JJ, Wells JD, Yoza BK, et al. Innate immune response to pulmonary contusion: identification of cell type-specific inflammatory responses. Shock 2012;37:385-91.

44. Wu XJ, Xia ZY, Wang LL, et al. Effects of penehyclidine hydrochloride on pulmonary contusion from blunt chest trauma in rats. Injury 2012;43:232-6.

45. Hoth JJ, Wells JD, Hiltbold EM, et al. Mechanism of neutrophil recruitment to the lung after pulmonary contusion. Shock 2011; 35:604-9.

46. Abraham E, Carmody A, Shenkar R, et al. Neutrophils as early immunologic effectors in hemorrhage- or endotoxemia-induced acute lung injury. Am F Physiol Lung Cell Mol Physiol 2000;279:L1137-45.

47. Hoth JJ, Wells JD, Brownlee NA, et al. Toll-like receptor 4-dependent responses to lung injury in a murine model of pulmonary contusion. Shock 2009;31:376-81.

48. Li H, Su X, Yan X, et al. Toll-like receptor 4-myeloid differentiation factor 88 signaling contributes to ventilator-induced lung injury in mice. Anesthesiology 2010;113:619-29.

49. Seitz DH, Palmer A, Niesler U, et al. Altered expression of Fas receptor on alveolar macrophages and inflammatory effects of soluble Fas ligand following blunt chest trauma. Shock 2011;35:610-7.

50. Wang S, Zhang H, Wang A, et al. PHLDA1 promotes lung contusion by regulating the toll-like receptor 2 signaling pathway. Cell Physiol Biochem 2016;40:1198-206.

51. Keel M, Ecknauer E, Stocker R, et al. Different pattern of local and systemic release of proinflammatory and anti-inflammatory mediators in severely injured patients with chest trauma. 7 Trauma 1996;40:907-12.

52. Muehlstedt SG, Richardson CJ, Lyte M, et al. Systemic and pulmonary effector cell function after injury. Crit Care Med 2002;30:1322-6.

53. Davis KA, Fabian TC, Croce MA, et al. Prostanoids: early mediators in the secondary injury that develops after unilateral pulmonary contusion. 7 Trauma 1999;46:824-31. 